\title{
Expressed Emotion among Caregivers of Person with Schizophrenia and Obsessive Compulsive Disorder: A Comparative Study
}

\author{
Jaya Bharti ${ }^{1 *}$
}

\section{ABSTRACT}

Background: This is a cross-sectional comparative study with the aim to compare two patient groups of schizophrenia and obsessive compulsive disorder (OCD) and their respective caregivers with the objectives to quantify and compare the expressed emotion (EE) in caregivers of person with schizophrenia and OCD and to study the relationship between them. It also aimed to identify factors associated with expressed emotions in above two groups. Methods: In this study, 40 patients schizophrenia, 40 patients of OCD, along with their 80 respective caregivers were taken on the basis of inclusion and exclusion criteria. Subjects were assessed using Sociodemographic and clinical sheet \&FEICS. Appropriate statistics such as mean, standard deviation, unpaired t test, Pearson's correlation were applied to analyse the data. Result: The results of the study the caregivers of patients with OCD were perceived as having greater over-involvement than the caregivers of schizophrenia. Perceived criticism had a positive correlation with stress whereas over-involvement had a negative correlation. Some of the demographic variables like age and education were also found to have significant correlation with expressed emotion. Conclusion: The presence of significant amount of expressed emotion point out to the need for psychosocial support to the family members for reduction in the expressed emotion.

Keywords: Expressed Emotion, Chronic Mental Illness, Caregivers

Expressed emotion, is a qualitative measure of the 'amount' of emotion displayed, typically in the family setting, usually by a family or care takers. Theoretically, a high level of EE in the home can worsen the prognosis in patients with mental illness or act as a potential risk factor for the development of psychiatric disease. The three dimensions of high EE shown are hostility, emotional over-involvement and critical comments. The stress from high expressed emotion may cause the patient to relapse. The patient falls into a cycle of rehabilitation and relapse because the stress builds up too much so the only escape is relapse and then the disorder is unsustainable and rehabilitation is required. The only way to escape this cycle is for the family to go through therapy together. This will greatly lower family conflicts and the stress level of the household.

\footnotetext{
${ }^{1}$ Research Scholar, University of Lucknow, Uttar Pradesh

*Corresponding Author

(C) 2015 I J Bharti; licensee IJIP. This is an Open Access Research distributed under the terms of the Creative Commons Attribution License (http://creativecommons.org/licenses/by/2.0), which permits unrestricted use, distribution, and reproduction in any Medium, provided the original work is properly cited.
} 


\section{Expressed Emotion among Caregivers of Person with Schizophrenia and Obsessive Compulsive Disorder: A Comparative Study}

Several decades of research have established EE as a highly reliable psychosocial predictor of psychiatric relapse. When patients live in a family environment that is characterized by critical, hostile, or emotionally over involved or intrusive attitudes (i.e., in high-EE families), they are at significantly elevated risk of early relapse compared with patients who do not live in such a family environment. The association between high levels of EE and symptom relapse has been well demonstrated for disorders such as schizophrenia and depression. The predictive validity of EE has also been found for a broad range of other psychopathological conditions, including anxiety disorders and substance abuse.

\section{The Components of Expressed Emotion}

George Brown explained five components of EE which includes

1. Critical comments

2. Hostility

3. Emotional over involvement (EOI)

4. Positive remarks

5. Warmth

Critical comments, hostility and EOI denote high expressed emotion while positive remarks and warmth indicate low EE. High EE relatives less tolerant, less flexible, and more conscientious and report feeling more burdened in the caretaking role. The quantification of critical comments and hostility is greatly reliant on the way in which the respondent uses their tone of voice to convey their feelings (anger, rejection, irritability, ignorance, blaming, negligence, etc.) while the judgment of over involvement also takes into account on the basis of reported behaviour such as caregivers blaming themselves, sacrificing things, being overprotective of patients, excessively being concerned for patients, neglecting personal needs of self, and similar others. Critical attitudes are combinations of hostile and emotional over-involvement. It shows openness that the disorder is not entirely in the patients control but there is still negative criticism. These are basically counted during the interview. Careful observations of direct communications among patients and caregivers prove that Critical caregivers get involved in angry exchanges with the patient whom they seem unable to prevent or to step away from. These potentially lead to physical Violence and it is the nature of some families with high EE. Patients who are unable to get up in the morning, who fail to wash regularly, or who do not participate in household tasks are criticized for being lazy and selfish; unfortunately, in this context, the caregivers fail to understand that these could be potential manifestations of negative symptoms of schizophrenia or any other psychotic disorder. This is reflected in the fact that $70 \%$ of critical comments were found to focus on these negative symptoms of schizophrenia rather than on the florid symptoms of delusions and hallucinations. Family caregiver may express in an increased tone, tempo, and volume that patient frustrates them, deliberately causes problems for them. By contrast, low EE caregivers are more capable to recognize aspects of the patient's behaviour which are a manifestation of the illness. 


\section{Expressed Emotion among Caregivers of Person with Schizophrenia and Obsessive Compulsive Disorder: A Comparative Study}

\section{HOSTILITY}

Hostility is a negative attitude directed at the patient because the family feels that the disorder is controllable and that the patient is choosing not to get better.

Problems in the family are often blamed on the patient and the patient has trouble problem solving in the family. The family believes that the cause of many of the family's problems is the patient's mental illness, whether they are or not. Hostility is expressed by general criticisms or attitudes that are rejecting of the patient.

\section{EMOTIONAL OVERINVOLVEMENT}

It is termed emotional over-involvement when the family members blame themselves for the mental illness. EOI manifests itself by over-emotionality, excessive self-sacrifice, overidentification, and extreme overprotective behaviour with the patient. These family members feel that any negative occurrence is their fault and not the disorders and suffer from chronic guilt. The family member shows a lot of concern for the patient and the disorder. This is the opposite of a hostile attitude and a show that the family member is open minded about the illness, but still has the same negative effect on the patient. Unfortunately, this discourages the person's skills and self-reliance, so that in the long run, over protectiveness hampers the person's recovery. It also leads to dependence of the patient on their caregiver. The pity from the relative causes too much stress and the patient relapses to cope with the pity.

EOI is most commonly shown by parents, especially mothers, and occasionally by fathers, but rarely by other relatives.

\section{WARMTH}

It is assessed based on kindness, concern, and empathy expressed by the caregiver while talking about the patient. It depends greatly on vocal qualities with smiling being a common accompaniment, which often conveys an empathic attitude by the relative. Warmth is a significant characteristic of the low EE family.

\section{POSITIVE REGARD}

Positive regard comprises of statements that express appreciation or support for Patient's behaviour and verbal/nonverbal reinforcement by the caregiver.

\section{Measuring Expressed Emotion}

There is a scale that is used in the Camber well Family Interview of the family to categorize. The three major expressed emotion scales are critical, hostility, and emotional over-involvement that are used to determine whether the expressed emotion is high or low (Hooley \& Hoffman 1999). All of the scales are taken into consideration while watching the tape of the relatives that were interviewed. The answers and reactions of the family members are carefully observed. Those in 


\section{Expressed Emotion among Caregivers of Person with Schizophrenia and Obsessive Compulsive Disorder: A Comparative Study}

the interview with high expressed emotion were considered very critical and not very tolerant of the feelings of the patient (Hooley, 1986). This attitude comes across too strong for someone who is trying to make progress in an illness. The person with the illness now has to deal with their own sickness and the criticism from those needed for support through these tough times.

\section{High Expressed Emotion}

Once the taped is watched and carefully analysed, the type of expressed emotion is decided. Those who are decided to have high expressed emotion are very critical and hostile. They do not know any other way to help support the family member because they feel like they are helping. They feel that the illness is internal and can be controlled by this person. The only way they feel that the person will change their behaviour is through criticism which actually causes the relapse. (Wendel, Miklowitz, Richards, \& George, 2000). Those with high expressed emotion also criticize behaviours' that do not relate to the psychological disorder but more to the unique person. A person's attitude toward a person, especially when they are very critical, takes a long time to change their way of thinking. High expressed emotion is more likely to cause a relapse than low expressed emotion because of the aggressive verbal criticisms they made (Weisman, Nuechlerlein, Goldstein, \& Snyder, 1998).

\section{Low Expressed Emotion}

Low expressed emotion differs from high expressed emotion in that the relatives are more conservative with their criticism. Relatives feel that the family member does not have control over the disorder and sympathize with them. This is because there is also more information about disorders in which some relatives have more knowledge of the illness than others, which makes them more understanding and less critical. Families also vary because some do not have to put up with difficult family members that have a mental disorder. These are some reasons for expressed emotion to be low instead of high. The family is more educated and accepting of the disorder than those of high expressed emotion (Weisman et al., 1998). The disorder is accepted to be external, not internal and out of the control of the patient. The relatives may have some criticism about the disorder and the behaviour, but they do not always express it towards them (Wendel et al., 2000). Low expressed emotion is a different stress from high expressed emotion because it is less stress toward the patient.

There is another way to measure the amount of expressed emotion that is in a household, and it is taken from the point of view of the patient. The perception of everyone around them shows how they feel about what is thought of them and the disorder they have. A study was conducted with patients who have schizophrenia that will live in the same house as their parents. The patients would rate their parents according to a scale of care and protection. Those who rated their parents with high protection or low care were found to have a harder time with the illness if there too much contact with their parents (Cutting \& Docherty, 2000). The parents come across too strong or not strong enough for those who are dealing with schizophrenia. This causes the child 


\section{Expressed Emotion among Caregivers of Person with Schizophrenia and Obsessive Compulsive Disorder: A Comparative Study}

to think that the parent does not care about their independence. They feel that the parent does not trust their judgments on making the right decisions. This sort of attitude from a parent causes them to relapse and have trouble improving their health.

Parents can cause their child to relapse because of their behaviour toward the child. Those who blame themselves for their child's illness are higher in emotional over-involvement, commonly found in females (Peterson \& Docherty, 2004). They become too involved with their child because they feel like it is their fault that the illness exists. This type of emotion is overwhelming for someone who is trying to improve their life. The parent shows a lot of concern toward the child, but it does not necessarily mean that this is productive for them. The over involvement causes the child to feel trapped because they feel like they cannot do anything independently. This adds onto the entrapment they have with the psychological disorder that they are trying to handle. The overbearing parents make the child feel helpless because they do not have control; therefore, they fall back into bad habits of their illnesses. Illnesses such as bulimia, anorexia, alcoholism, schizophrenia, and others are triggered by these types of behaviours' from parents and other relatives. The child may feel like the outsider of their family because of the excessive attention they receive as a result of their disorder. The behaviour of everyone around them influences their decision to relapse or progress. (Linda A. McDonagh)

\section{CAREGIVERS PERSONALITY FACTORS AND EXPRESSED EMOTION}

Although precise reason for high or low EE attitudes in caregivers is not yet completely unravelled, it has been suggested that EE might partially reflect caregiver's personality traits. Hooley and Hiller found that caregivers of schizophrenia patients, with high EE reported reduced satisfaction of their individual activities, reduced optimism about their future, and reduced selfefficacy compared with low EE caregivers. Moreover, caregivers of high EE were less empathic, rigid, and impatient than low EE caregivers. A critical comment of caregiver is dependent less on the degree of the patient's symptoms than on the caregiver's own personality factors. If a caregiver is easily adjusted to the difficult circumstances and has patience generally, he or she is likely to be a non-critical caregiver. If a caregiver is usually tense or irritable during stressful situations, this stress can result in feelings of anger. All these factors reveal that personality characteristics are significantly related to caregiver's high or low EE.

\section{OPERATIONAL DEFINITIONS:}

\section{Primary Care givers:}

A person who involved in direct care of a mentally ill patient and spent most of their time for caring the patient. This is usually the family member. Depending on culture there may be other members of the family engaged in care. Such as (Father, Mother or Husband, wife or Brother, Sister)-who are providing care for the mentally ill patients. 


\section{Expressed Emotion among Caregivers of Person with Schizophrenia and Obsessive Compulsive Disorder: A Comparative Study}

\section{Obsessive compulsive disorder (OCD):}

Obsessions are thoughts, images or impulses that occur over and over again and feel outside of the person's control. Individuals with OCD do not want to have these thoughts and find them disturbing. In most cases, people with OCD realize that these thoughts don't make any sense. Obsessions are typically accompanied by intense and uncomfortable feelings such as fear, disgust, doubt, or a feeling that things have to be done in a way that is "just right." In the context of OCD, obsessions are time consuming and get in the way of important activities the person values. This last part is extremely important to keep in mind as it, in part, determines whether someone has OCD - a psychological disorder - rather than an obsessive personality trait. Compulsions are the second part of obsessive compulsive disorder. These are repetitive behaviours' or thoughts that a person uses with the intention of neutralizing, counteracting, or making their obsessions go away. People with OCD realize this is only a temporary solution but without a better way to cope they rely on the compulsion as a temporary escape. Compulsions can also include avoiding situations that trigger obsessions. Compulsions are time consuming and get in the way of important activities the person values.

\section{Schizophrenia:}

Schizophrenia is a serious mental illness characterized by incoherent or illogical thoughts, bizarre behavior and speech, and delusions or hallucinations, such as hearing voices. Schizophrenia typically begins in early adulthood. Schizophrenia is a brain disorder that affects the way a person behaves, thinks, and sees the world. People with schizophrenia often have an altered perception of reality. They may see or hear things that don't exist, speak in strange or confusing ways, believe that others are trying to harm them, or feel like they're being constantly watched. This can make it difficult to negotiate the activities of daily life and people with schizophrenia may withdraw from the outside world or act out in confusion and fear.

\section{RATIONALE FOR THE PRESENT STUDY}

Expressed emotion has been studied in patients with Schizophrenia but literature is less regarding with other chronic mental. There are few studies on OCD. In this background, the present study will plan to quantify and compare the EE in caregivers of schizophrenia and OCD.

\section{OBJECTIVES}

The present study will aim at exploring and comparing the EE in caregivers of chronic mentally ill patient. The broad objective of this study is to critically examine the families of person with chronic mental illness and the challenges they face in living with the person and Following specific objectives were formulated:

1. To explore the impact of EE and their association with demographic factors like age, gender etc.

2. To quantify and compare the EE in caregivers of person with schizophrenia and OCD.

3. To estimate and compare the extent of expressed emotion in the above two populations 


\section{METHODOLOGY}

STUDY SETTING:

The study was conducted in selected Psychiatric Hospital at Lucknow (Uttar Pradesh).

\section{RESEARCH DESIGN:}

This was a hospital-based, cross sectional and comparative study.

\section{POPULATION:}

The population of the present study will include primary care givers of patients who are diagnosed as schizophrenia \& OCD. On the basis of ICD-10 in a selected psychiatric hospital at Lucknow.

\section{SAMPLE:}

Total subjects in caregiver group 80 (40 caregivers of person with schizophrenia, and 40 caregiver's person with OCD respectively were taken up for study).

\section{SAMPLING PLAN:}

Purposive sampling technique was used to select the samples for the study.

\section{SAMPLING CRITERIA-}

\section{Inclusion Criteria for chronic Mentally Ill Patients}

$\checkmark$ Age group ranging from 18-60 years

$\checkmark$ Patients diagnosed as schizophrenia, OCD according to ICD-10

$\checkmark$ Duration of illness at least 2 years recruited to the study

\section{Exclusion Criteria for Chronic Mentally Ill Patients}

$\checkmark$ Neurological disorders such as seizures, movement disorders, cerebral palsy

$\checkmark$ Recent or current medical illness

$\checkmark$ Co morbidity with any other psychiatric disorder.

$\checkmark$ Use of any pharmacological intervention other than psychotropic drugs.

$\checkmark$ Life time history of head injury associated with loss of consciousness, seizures, neurological deficits, or surgical intervention.

\section{Inclusion Criteria for Caregivers}

$\checkmark$ Primary caregivers (Parents/Spouse/Sibling/Children)who are staying with the patient since the onset of illness are included.

$\checkmark$ Age group above 21 years

$\checkmark$ Living with the patient for at least last 1 year

$\checkmark$ Those who gave informed consent to participate in the study 


\section{Exclusion Criteria for Caregivers}

$\checkmark$ Caregivers with psychiatric conditions, organic syndromes, mental retardation, substance dependence or chronic physical illness.

$\checkmark$ Those who did not give consent

\section{DATA COLLECTION PROCEDURES}

\section{Tools Used}

The following tools were used for the present study:

\section{A. SOCIODEMOGRAPHIC AND CLINICAL SHEET}

A semi-structured proforma will design to collect demographic information like age, sex, duration of marriage, etc. about the patients and their caregivers along with the clinical information like the age of onset, duration of illness, number of hospitalizations, etc. regarding the patient.

\section{FAMILY EMOTIONAL INVOLVEMENT AND CRITICISM SCALE (SHIELDS ET AL)} It is a self-report scale assessing perceived criticism and intensity of emotional involvement. Cronbach's alpha is 0.82 for Perceived Criticism subscale and 0.74 for Emotional Involvement subscale. Findings suggest that FEICS is reliable instrument for measuring expressed emotion. This is a 14-item scale with two subscales: Perceived Criticism and Intensity of Emotional Involvement. Both the scales have seven items each and are scored on Likert scale ranging from 1 to 5 . Higher score indicates higher EE by the family members.

\section{ETHICAL ISSUES}

1- A fully informed consent was taken from all participants in the study prior to data collection

2- Subjects had the right to withdraw from the study at any point of time during the course of the study.

3- The confidentiality of the subject was maintained through the course of the study and was shared with the treating team when deemed beneficial for the patient's management

\section{PROCEDURE}

The study was approved by the hospitals ethics committee, and all subjects gave written informed consent to participate. Person with Schizophrenia, person with OCD and their caregivers were selected by purposive sampling on the basis of inclusion and exclusion criteria from out patients of the hospitals. Detailed data was collected on the socio-demographic and clinical data sheet designed for the purpose. 


\section{RESULTS}

Table 1: Sociodemographic Characteristics of caregivers of person with Schizophrenia $(N=40)$ and Schizoaffective Disorder $(N=40)$

\begin{tabular}{|c|c|c|c|c|c|c|}
\hline \multicolumn{2}{|c|}{ Characteristics } & \multirow{3}{*}{$\begin{array}{l}\text { Caregivers } \\
\text { Schizophrenia } \\
\text { N (\%) } \\
661 \%\end{array}$} & \multirow{3}{*}{$\begin{array}{l}\text { Caregivers } \\
\text { OCD } \\
\text { N (\%) } \\
58.4 \%\end{array}$} & \multirow{4}{*}{\begin{tabular}{|l}
$d f$ \\
1,1
\end{tabular}} & \multirow{4}{*}{$\begin{array}{l}\text { CHI } \\
\text { SQUARE } \\
\\
0.053\end{array}$} & \multirow{4}{*}{\begin{tabular}{|l} 
P value \\
NS \\
\end{tabular}} \\
\hline \multirow[t]{3}{*}{ Gender } & & & & & & \\
\hline & Male & & & & & \\
\hline & Female & $43.3 \%$ & $41 \%$ & & & \\
\hline \multirow{3}{*}{$\begin{array}{l}\text { Marital } \\
\text { Status }\end{array}$} & & $15 \%$ & $12 \%$ & \multirow[t]{3}{*}{1,1} & \multirow[t]{3}{*}{0.459} & \multirow[t]{3}{*}{ NS } \\
\hline & Married & & & & & \\
\hline & Unmarried & $84 \%$ & $91 \%$ & & & \\
\hline \multirow[t]{2}{*}{ Occupation } & Employed & $41.5 \%$ & $48.9 \%$ & \multirow[t]{2}{*}{2,1} & \multirow[t]{2}{*}{0.203} & \multirow[t]{2}{*}{ NS } \\
\hline & Unemployed & $55.6 \%$ & $54.7 \%$ & & & \\
\hline \multirow{3}{*}{ Education } & & $51 \%$ & $66.5 \%$ & \multirow[t]{3}{*}{1,1} & \multirow[t]{3}{*}{0.464} & \multirow[t]{3}{*}{ NS } \\
\hline & $\begin{array}{l}\text { Above } \\
\text { Matric }\end{array}$ & & & & & \\
\hline & $\begin{array}{l}\text { Below } \\
\text { Matric }\end{array}$ & $43.2 \%$ & $39.6 \%$ & & & \\
\hline
\end{tabular}

The study sample consisted of caregivers of 40 people with schizophrenic and 40 people with OCD. Table 1 shows the comparison of socio-demographic variables among caregiver groups. There were no significant differences with respect to Gender $\left(X^{2}=0.053\right)$, marital status $\left(\mathbf{X}^{2}=0.459\right)$, Education $\left(\mathbf{X}^{2}=0.203\right)$ as well as Occupational status $\left(\mathbf{X}^{2}=0.464\right)$ among the two groups. Most caregivers had studied below high school $.48 .9 \%$ of caregivers of Person with OCD were employed compared to $41.5 \%$ of caregivers of person with schizophrenia.

Table 2: Comparison of Expressed Emotion in Two Groups of Caregivers (Schizophrenic and OCD)

\begin{tabular}{|l|l|l|l|l|l|l|}
\hline MEASURES & Grouping & $\mathrm{N}$ & Mean & $\mathrm{SD}$ & $\begin{array}{l}\mathrm{t} \\
\text { Value }\end{array}$ & $\begin{array}{l}\mathrm{P} \\
\text { Value }\end{array}$ \\
\hline \multirow{2}{*}{ FEICS EOI } & schizophrenia & 40 & 2.72 & 0.70 & 3.62 & 0.01 \\
\cline { 2 - 6 } & OCD & 40 & 3.39 & 1.06 & & \\
\hline \multirow{2}{*}{ FEICS PC } & schizophrenia & 40 & 3.71 & 0.49 & 1.62 & NS \\
\cline { 2 - 5 } & OCD & 40 & 3.41 & 0.97 & & \\
\hline
\end{tabular}




\section{Expressed Emotion among Caregivers of Person with Schizophrenia and Obsessive Compulsive Disorder: A Comparative Study}

Table 2: shows comparison of expressed emotion with independent sample $t$ test, in the two groups as reflected in FEICS scoring. Emotional over-involvement (FEICS EOI) was significantly more in patients with OCD with mean 3.39(SD=1.06) compared to patients with Schizophrenia with mean $2.72(\mathrm{SD}=0.70)$, with $\mathrm{t}=3.62 \mathrm{p}$ value $<0.01$. There was no significant difference in perceived criticism (FEICS PC) experienced in both groups.

Table 3: Correlation (R) Of Expressed Emotion with Sociodemographic Variables Of The Caregivers In Study Population

\begin{tabular}{|l|l|l|}
\hline Characteristics & $\begin{array}{l}\text { FEICSEOI } \\
\text { (Emotional over involvement) }\end{array}$ & $\begin{array}{l}\text { FEICSPC } \\
\text { (Perceived criticism) }\end{array}$ \\
\hline Age & .073 & .171 \\
\hline Sex & .022 & .012 \\
\hline Religion & .079 & .034 \\
\hline Marital status & .129 & .289 \\
\hline Education & .027 & .202 \\
\hline Occupation & .067 & .058 \\
\hline Residence & .029 & .207 \\
\hline SES & .055 & .168 \\
\hline Family history & .119 & .185 \\
\hline
\end{tabular}

Table 3 shows Pearson correlation between socio-demographic profile of patients and expressed emotion respectively. Correlation (r) values are shown in the table. Those who were single had perceived higher criticism $(\mathrm{r}=0.289)$. No other significant correlation was observed.

\section{DISCUSSION}

This study was conducted on person with schizophrenia and OCD disorder and their caregivers.

\section{DISCUSSION OF METHODOLOGY}

The sample size in the present study was 80 in the patient group and 80 in the caregiver group. Thus 40 patients of schizophrenia, 40 patients of OCD and there 80 respective caregivers were included in the study. To examine the sufficiency of the sample, previous related studies were reviewed. The studies on expressed emotion were less. Family emotional involvement and criticism scale (FEICS) by Shields et al were used in the present study to assess expressed emotion respectively. FEICS is also a reliable instrument which has been used in Indian studies for assessment of expressed emotion. Socio-demographic variables such as sex, marital status, residence were compared using chi square. There were no significant differences in the socio demographic profile of patients or caregivers in both groups. Hence, the groups were comparable. The mean age of onset was significantly higher in schizophrenia than OCD. 


\section{CONCLUSIONS}

The primary aim of the study was to estimate and compare expressed emotion in caregivers of the patients with schizophrenia and OCD. The caregivers of OCD patients were perceived as having greater over-involvement than the caregivers of schizophrenia. Perceived criticism has a positive correlation with workload whereas over-involvement is having a negative correlation. Some of the demographic variables like age and education are also found to have significant correlation with expressed emotion. The presence of significant amount expressed emotion point out to the need for psychosocial support to the family members for reduction in the expressed emotion which in turn could reduce the relapse rates and facilitate the caregivers to effectively cope and manage the ill family member. Additional studies would be required to further delineate the factors associated with expressed emotion in the caregivers. In the present study emotional over-involvement was significantly more in OCD group but perceived criticism was more in patients with schizophrenia which however could not reach statistical significance. Studies have reported interactional differences in schizophrenia and OCD patients. The analysis of demographic correlates of expressed emotion revealed that younger the patient more was the expressed emotion. Patients who were single experienced significantly more expressed emotion than married persons.

\section{LIMITATIONS}

1. Sample size was modest, which makes it difficult to generalize the result.

2. Random sampling was not done.

3. Examiner who rated the subjects on the BAS and FEICS scale were not blind to the diagnosis, which might have caused rater bias in the evaluation of the subject.

4. All patients in this study were receiving antipsychotics and/or mood stabilizers, which may have had an effect in this study.

\section{Key points}

1. Studies controlling for the effects of confounding factors like effects of medicines, total number of episodes, psychopathology, with a larger sample may be done to increase the power of study.

2. On BAS, caregivers of patients with schizophrenia reported significantly more burden than those of obsessive compulsive disorder

3. Expressed emotion was perceived more in younger, single and more educated patients

4. Interventional studies may be done to target caregiver burden and its effect can be assessed on expressed emotion in patients of schizophrenia and obsessive compulsive disorder. 
REFERENCES:

Abramowitz, J.S. (2006). The Psychological Treatment of Obsessive-Compulsive Disorder. Canadian Journal of Psychiatry, 51(7), 407-16

American Psychiatric Association. Diagnostic and statistical Manual of Mental Disorders, fifth edition. Arlington, VA: American Psychiatric Association; 2013.p.105-110.

Chang K H , Horrock S, "Lived experiences of care givers of mentally ill relatives” Journal of Advanced Nursing, Feb 2006; 53(4);435-443.

Dr Lalitha K, "Mental health and psychiatric Nursing; An Indian Perspectives", first edition VMG Book House Bangalore 2007; 16.

Hoenig J, Hamilton MW. The schizophrenic patient in the community and his effects on the household. International Journal of Social Psychiatry 1966; 12:165- 176.

Magana AB, Goldstein MJ, Kamo M, Miklowitz DJ, Jenkins J, Falloon IR. Abrief method for assessing expressed emotion in relatives of psychiatric patients.Psychiatry Res 1986;17:203

Mathew Samuel, Murali Thyloth, “Care givers roles in India”, Psychiatric Services 53:346-347, March 2002.

Natalie, C. Ian. Steve, H. and Paul, H. Measuring chronic patients' feelings of being a burden to their caregivers. Development and preliminary validation of a

National Institute of Mental Health (2012). Obsessive Compulsive Disorder among Adults. Available online

NICE (2005). Obsessive-compulsive disorder: core interventions in the treatment of obsessivecompulsive disorder and body dysmorphic disorder

of schizophrenia. 2005 PLoS Med 2, e141.

Pai S. Kapur RL. The burden on the family of a psychiatric patient: Development of an interview schedule. Brit J Psychiatry 1981; 138:332-335.

persons with schizophrenia. Indian J Psychiatry 2002; 44(3):220-227

Raj L, Kulhara P, Avasthi A. Social burden of positive and negative schizophrenia. International J Soc Psychiatry 1991; 37:242-250.

Rammohan A, Rao K, Subbakrishna DK. Burden and coping in caregivers of

Raune D, Kuipers E, Bebbington PE (April 2004). "Expressed emotion at first-episode psychosis: investigating a carer appraisal model". $\mathrm{Br} \quad \mathrm{J}$ Psychiatry 184: $321-$ 6. doi:10.1192/bjp.184.4.321. PMID 15056576

Saha S, Chant D, Welham J, McGrath J. A systematic review of the prevalence

Scale. Official Journal of Medical Care Section, American Public Health Association, 2003; 41 (1): 110-118.

T.B Ustun, J L Ayuso, S Chatterji, “Global burden of depressive disorders in the year 2000”, the British Journal of Psychiatry 2004; 184:386-392.

Thara R, Srinivasan TN.How stigmatizing is schizophrenia in India? Int J Soc Psychiatry 2000; 46(2):135-141.

World Health Organization, Burden of Mental Health and Behavioural Disorders, the World Health Report, Mental Health: New Understanding. New Hope;Genava,World Health Organization2001

Webs

http://www.helpguide.org

http://www.personalityresearch.org 